\title{
PREDICTION AND OPTIMIZATION OF SURFACE ROUGHNESS IN GRINDING OF S5OC CARBON STEEL USING MINIMUM QUANTITY LUBRICATION OF VIETNAMESE PEANUT OIL
}

\section{Scopus

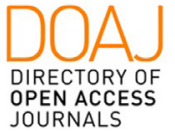

Crossref

\section{Nguyen Thuy Duong}

Hanoi University of Science and Technology, School of Mechanical Engineering, Hanoi, Vietnam

\section{Dao Ngoc Hoanh}

Hanoi University of Industry, Faculty of Mechanical Engineering, Hanoi, Vietnam

\section{Hoang Tien Dung}

Hanoi University of Industry, Faculty of Mechanical Engineering, Hanoi, Vietnam
Nguyen Van Canh

Hanoi University of Industry, Faculty of Mechanical Engineering, Hanoi, Vietnam

\section{Do Minh Hien}

Hanoi University of Industry, Faculty of Mechanical Engineering, Hanoi, Vietnam

\section{Van Thien Nguyen}

Hanoi University of Industry, Faculty of Mechanical Engineering, Hanoi, Vietnam

Key words: grinding, minimum quantity lubricant, optimization, regression optimizer, multi-response optimization

doi: $10.5937 /$ jaes0-30580

\section{Cite article:}

Duong, N. T., Dung, H. T., Canh, N. V., Hoanh, D. N., Hien, D. M., Nguyen, V. T. (2021)

PREDICTION AND OPTIMIZATION OF SURFACE ROUGHNESS IN GRINDING OF S50C CARBON STEEL USING MINIMUM QUANTITY LUBRICATION OF VIETNAMESE PEANUT OIL, Journal of Applied Engineering Science, 19(3), 814-821, DOI:10.5937/jaes0-30580

Online aceess of full paper is available at: www.engineeringscience.rs/browse-issues 


\title{
PREDICTIONANDOPTIMIZATIONOFSURFACEROUGHNESS IN GRINDING OF S5OC CARBON STEEL USING MINIMUM QUANTITY LUBRICATION OF VIETNAMESE PEANUT OIL
}

\author{
Nguyen Thuy Duong ${ }^{1 *}$, Hoang Tien Dung ${ }^{2}$, Nguyen Van Canh ${ }^{2}$, Dao Ngoc Hoanh ${ }^{2}$, Do Minh Hien ${ }^{2}$, Van Thien \\ Nguyen ${ }^{2}$
}

${ }^{1}$ Hanoi University of Science and Technology, School of Mechanical Engineering, Hanoi, Vietnam

${ }^{2}$ Hanoi University of Industry, Faculty of Mechanical Engineering, Hanoi, Vietnam

This experimental research aimed to build the regression model of grinding S50C carbon steel based on a Regression Optimizer. The workpiece specimens were JIS S50C carbon steel that was hardened at 52HRC. Taguchi L27 orthogonal array was performed with 53 -levels-factors. The studied factors were combining cutting parameters, such as cutting speed, feed rate, depth of cut, and lubricant parameters, including air coolant flow rate $Q$ and air pressure $P$. The results show that cutting parameters includes workpiece velocity $V_{w^{\prime}}$ feed rate $f$, and depth of cut ap, influence the most on surface roughness $R_{a}$, Root Mean Square Roughness $R_{q^{\prime}}$, and Mean Roughness Depth $R_{z^{\prime}}$. By contrast, the influence of lubrication parameters is fuzzy. Therefore, this present work focused on predicting and optimizing $R a$, $R_{z}, R_{q}$ in surface grinding of JSI S50C carbon steel using MQL of peanut oil. In this work, combining of grinding parameters and lubrication parameters were considered as input factors. The regression models of $R_{a}, R_{z}$, and $R_{q}$ were obtained using Minitab 19 by Regression Optimizer tool, and then the multi-objective optimization problem was solved. The present findings have shown that Vietnamese vegetable peanut oil could be considered as the lubricant in the grinding process. The optimum grinding and lubricant parameters as following: the workpiece velocity $V w$ of $5 \mathrm{~m} / \mathrm{min}$, feed rate $f$ of $3 \mathrm{~mm} / \mathrm{stroke}$, depth of cut of $0.005 \mathrm{~mm}$ and oil flow rate, air pressure of $91.94 \mathrm{ml} / \mathrm{h}, 1 \mathrm{MPa}$, respectively. Corresponding to the surface roughness $R_{a}$, Root Mean Square Roughness $R_{q^{\prime}}$ and Mean Roughness Depth $R_{z}$ of $0.6512 \mu \mathrm{m}, 4.592 \mu \mathrm{m}, 0.8570 \mu \mathrm{m}$, respectively.

Key words: grinding, minimum quantity lubricant, optimization, regression optimizer, multi-response optimization

\section{INTRODUCTION}

JIS S50C carbon steel is popular in the manufacturing industry due to its suitable characteristics. The S50C steel could be manufactured under metal forming processes such as hot forging, cold forging... or under metal cutting processes like grinding, turning, milling... the essential criteria that have to consider in the cutting of S50C is surface roughness. In traditional machining processes, metal cutting fluid (WMF) is often used to reduce the cutting zone's temperature, tool wear... and improve surface quality by reducing the friction between the cutting tool and workpiece [1]. Due to the increase of competition in the global market and forward to sustainable manufacturing, reducing cutting fluid was new wattage that was considered research. Many published research studies have shown that MQL is applied in grinding carbon steel and improves the surface quality contemporaneously [1]-[4]. Akash Subhash Awale et al. [5] carried out a multi-objective optimization in the grinding process assisted minimum quantity lubricant. The author claimed that controlling the cutting parameters and using optimal lubricant settings improves surface quality and reduces the tool wear.

In the recent few decades, many different optimization methods were presented to optimize surface roughness in the machining process, including milling, turning, grinding. However, the manufacturers have to consider improving the product's quality while reducing the cost due to the highly competitive market. Hence, multiple objective optimizations were more popular recently. Many researchers performed Taguchi and Taguchi-based optimization techniques because of their advantages [6]-[8], minimizing the number of experiments. Hung-Chang Liao et al. [6] successfully applied the DEAR-based Taguchi method in multiple optimization issues and compared it to the PCA method. The work-study has shown that Taguchi and other Taguchi based techniques are a powerful tool to solve multi-criteria optimization, where the DEAR approach performed better than Taguchi and PCA techniques. Mia et al. [7] carried out research applying Taguchi S/N (signal/Noise) ratio in multiple optimizations in the hard assisted MQL turning of AISI 1060 steel process, concentrate on increasing material removal rate and minimizing surface roughness and tool wear at the same time. The research's results revealed that selecting a grinding parameter set: $V_{c}$ of $90 \mathrm{~m} / \mathrm{min}$, feed rate $f$ of $0.2 \mathrm{~mm} / \mathrm{rev}$, and ap at $1.5 \mathrm{~mm}$ provides the best quality surface and maximum production rate. Many other study results have shown that Taguchi based techniques are robust and easy to use to solve multi-objective optimization. But the disadvantage of these methods can be used to rank and find the best alternative instead of predicting the exact parameter set. Due to the lack of these methods, some new techniques, formulas....were announced 
to solve multiple criteria problems, such as coupling method of response surface (CMRS) [9], Artificial Neural Network (ANN) [10]-[13]... or computer software to build the regression model then predict the parameter sets corresponding to the optimum desired manufacturing responses. In this present work, computing software namely regression optimizer was selected to build the regression models then solve the multi-objective optimization problems. The Vietnamese peanut oil was used as the MQL lubricant.

\section{RESEARCH METHODOLOGY}

\section{Experimental material}

Experimental workpiece is S50C carbon steel with 52 HRC hardness after heat treatment. The chemical composition of S50C steel is present in Table 1.

Table 1: S50C steel Chemical Composition

\begin{tabular}{|c|c|c|c|c|c|c|c|}
\hline \multirow{2}{*}{$\mathrm{C}(\%)$} & \multirow{2}{*}{$\mathrm{Si}(\%)$} & \multirow{2}{*}{$\mathrm{Mn}(\%)$} & $P(\%)$ & $\mathrm{S}(\%)$ & $\mathrm{Cr}(\%)$ & $\mathrm{Ni}(\%)$ & $\mathrm{Cu}(\%)$ \\
\hline & & & $\max$ & $\max$ & $\max$ & $\max$ & $\max$ \\
\hline $\begin{array}{c}0.47- \\
0.55\end{array}$ & $\begin{array}{c}0.17- \\
0.37\end{array}$ & $\begin{array}{l}0.50- \\
0.80\end{array}$ & 0.035 & 0.035 & 0.25 & 0.25 & 0.25 \\
\hline
\end{tabular}

\section{The experimental machine and measurement equipment}

The machine grinding APSG-820/2A was used for this experiment procedure. The surface roughness $\mathrm{Ra}$, Root Mean Square Roughness $\mathrm{R}_{\mathrm{q}}$ and Mean Roughness Depth $R_{z}$ were measured by Surftest JS-201 of Mitutoyo (Japan).

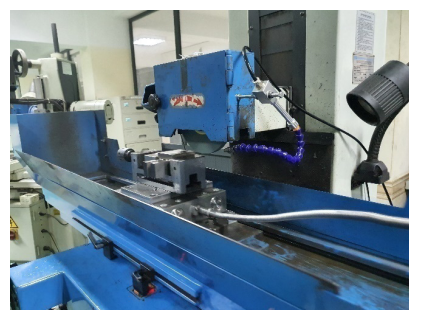

Figure 1: Experimental grinding machine

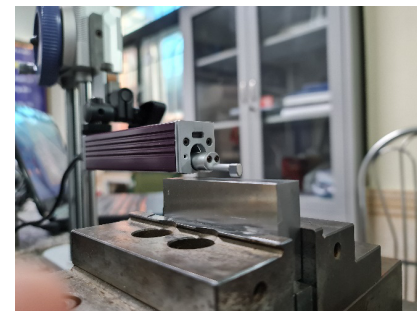

Figure 2: Mitutoyo Surftest JS-210

Each experimental was measured 3 times at 3 separate positions, the measured results were filled in Table 3 .

\section{MQL Iubrication}

Vegetable peanut oil was used for MQL Lubrication in this experimental procedure according to the results of previous publication.

\section{The experimental design}

In this study work, Taguchi Orthogonal Array was applied to design the experimental matrix. The five three-level input factors and their values werelisted in Table 2.

According to the number of input factors and the level of each factor, the Taguchi's orthogonal array L27(313) was used. The experimental matrix designed by Minitab 19, and has shown as Table 2.

The grinding parameters were selected according to the specification of grinding machine, where the level 1 and level 3 are the lower and upper limitation of parameter, respectively. And, level 2 are the average value of level 1 and level 3 values.

$R_{a}$ is surface roughness; the values were determined by the formula (1), according to EN ISO 4287:1997 [14]

$R_{a}=\frac{1}{l} \int_{0}^{l}|Z(x)| d x$

Where: $\mathrm{Z}(\mathrm{x})$ is the arithmetic mean of the absolute ordinate within the sampling length.

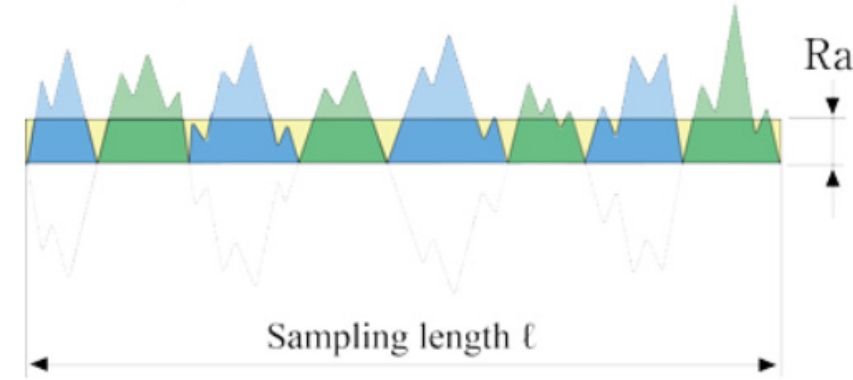

Figure 3: Surface Roughness Ra and RMS Roughness $R q$ [14]

$\mathrm{Rz}$ is Mean Roughness Depth. The values were calculated as [14]:

$R_{z}=R_{p}+R_{v}$

$\mathrm{Rq}$ is Root Mean Square (RMS) Roughness. The RMS Values were determined as [14]:

$R_{q}=\sqrt{\frac{1}{I} \int_{0}^{l} Z^{2}(x) d x}$

Table 2: MQL parameters, Grinding parameters and their level

\begin{tabular}{|c|c|c|c|c|c|}
\hline Parameters & Symbol & Dimension & Level 1 & Level 2 & 100 \\
\hline Flow rate & $\mathrm{Q}$ & $\mathrm{ml} / \mathrm{h}$ & 50 & 4 & 6 \\
\hline Air pressure & $\mathrm{P}$ & $\mathrm{MPa}$ & 2 & 10 & 15 \\
\hline Workpiece Velocity & $\mathrm{Vw}$ & $\mathrm{m} / \mathrm{min}$ & 5 & 5 & 7 \\
\hline Feed rate & $\mathrm{f}$ & $\mathrm{m} / \mathrm{stroke}$ & 3 & 0.010 & 0.015 \\
\hline Depth of cut & $\mathrm{ap}$ & $\mathrm{mm}$ & 0.005 & & \\
\hline
\end{tabular}




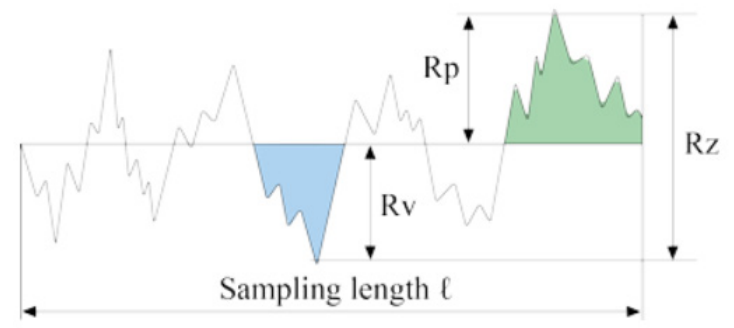

Figure 4: Ten point height of irregularities, Rz [14]

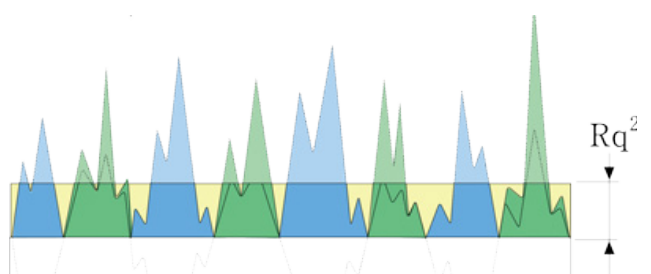

Sampling length $\ell$

Figure 5: Root mean square roughness [14]

\section{Experimental procedure}

Each workpiece specimen was grinded following by the run of experimental matrix. The surface roughness were measured by JS-210 surftest and the results were listed in Table 3.

\section{RESULTS AND DISCUSSION}

\section{Taguchi Analysis}

\section{Influence of input factors on surface roughness $R_{a}$}

Table 4: Response table for signal to noise ratios for $R_{a}$

\begin{tabular}{|c|c|c|c|c|c|}
\hline Level & $\mathrm{Q}$ & $\mathrm{P}$ & $\mathrm{V}_{\mathrm{w}}$ & $\mathrm{F}$ & $\mathrm{t}$ \\
\hline 1 & 0.25905 & 0.59043 & 0.52979 & 1.98365 & 0.97511 \\
\hline 2 & 0.15145 & 0.02601 & 0.28287 & -0.22556 & 0.09922 \\
\hline 3 & 0.12136 & -0.08457 & -0.28079 & -1.22622 & -0.54246 \\
\hline Delta & 0.13769 & 0.67500 & 0.81058 & 3.20987 & 1.51757 \\
\hline Rank & 5 & 4 & 3 & 1 & 2 \\
\hline
\end{tabular}

Table 3: Experimental and prediction results

\begin{tabular}{|c|c|c|c|c|c|c|c|c|c|}
\hline \multirow[b]{2}{*}{ Runs } & \multirow[b]{2}{*}{$\mathrm{V}_{\mathrm{w}}$} & \multirow[b]{2}{*}{$f$} & \multicolumn{3}{|c|}{ Experimental Results } & \multicolumn{3}{|c|}{ Prediction Results } & \multirow[b]{2}{*}{$\mathrm{R}_{\mathrm{a}}$} \\
\hline & & & $a_{p}$ & $\mathrm{R}_{\mathrm{q}}$ & $\mathrm{R}_{\mathrm{z}}$ & $\mathrm{R}_{\mathrm{a}}$ & $\mathrm{R}_{\mathrm{q}}$ & $R_{z}$ & \\
\hline 1 & 5 & 3 & 0.005 & 0.857 & 4.555 & 0.502 & 0.79092 & 4.56008 & 0.61358 \\
\hline 2 & 5 & 3 & 0.010 & 0.890 & 5.672 & 0.540 & 0.94996 & 5.30668 & 0.7008 \\
\hline 3 & 5 & 3 & 0.015 & 0.988 & 5.266 & 0.864 & 1.08595 & 5.9605 & 0.78803 \\
\hline 4 & 10 & 5 & 0.005 & 1.331 & 6.341 & 0.939 & 1.18578 & 6.30386 & 0.89735 \\
\hline 5 & 10 & 5 & 0.010 & 1.323 & 6.767 & 1.020 & 1.29728 & 6.86332 & 0.98458 \\
\hline 6 & 10 & 5 & 0.015 & 1.368 & 7.144 & 1.215 & 1.39993 & 7.3805 & 1.07181 \\
\hline 7 & 15 & 7 & 0.005 & 1.559 & 7.543 & 1.036 & 1.47871 & 7.66048 & 1.18113 \\
\hline 8 & 15 & 7 & 0.010 & 1.644 & 8.460 & 1.343 & 1.56954 & 8.12709 & 1.26836 \\
\hline 9 & 15 & 7 & 0.015 & 1.684 & 8.342 & 1.231 & 1.65539 & 8.56832 & 1.35558 \\
\hline 10 & 10 & 7 & 0.005 & 1.425 & 7.094 & 0.929 & 1.37392 & 7.31399 & 1.05746 \\
\hline 11 & 10 & 7 & 0.010 & 1.366 & 8.085 & 1.136 & 1.47123 & 7.80135 & 1.14469 \\
\hline 12 & 10 & 7 & 0.015 & 1.454 & 7.837 & 1.220 & 1.56249 & 8.26 & 1.23191 \\
\hline 13 & 15 & 3 & 0.005 & 1.266 & 5.399 & 0.928 & 0.9308 & 5.17306 & 0.73713 \\
\hline 14 & 15 & 3 & 0.010 & 1.325 & 5.733 & 0.888 & 1.06923 & 5.84184 & 0.82435 \\
\hline 15 & 15 & 3 & 0.015 & 1.245 & 6.634 & 0.814 & 1.19169 & 6.44156 & 0.91158 \\
\hline 16 & 5 & 5 & 0.005 & 1.195 & 6.324 & 0.943 & 1.16348 & 6.35368 & 0.89274 \\
\hline 17 & 5 & 5 & 0.010 & 1.286 & 7.214 & 0.938 & 1.27693 & 6.90912 & 0.97997 \\
\hline 18 & 5 & 5 & 0.015 & 1.278 & 7.770 & 1.395 & 1.38109 & 7.42311 & 1.06719 \\
\hline 19 & 15 & 5 & 0.005 & 1.252 & 6.030 & 0.985 & 1.16101 & 6.36525 & 0.89724 \\
\hline 20 & 15 & 5 & 0.010 & 1.295 & 7.103 & 1.083 & 1.27468 & 6.91975 & 0.98446 \\
\hline 21 & 15 & 5 & 0.015 & 1.337 & 7.263 & 1.049 & 1.37902 & 7.43301 & 1.07169 \\
\hline 22 & 5 & 7 & 0.005 & 1.348 & 7.509 & 1.071 & 1.35471 & 7.35698 & 1.05285 \\
\hline 23 & 5 & 7 & 0.010 & 1.398 & 7.807 & 1.095 & 1.45331 & 7.84167 & 1.14007 \\
\hline 24 & 5 & 7 & 0.015 & 1.362 & 8.512 & 1.239 & 1.54563 & 8.29809 & 1.2273 \\
\hline 25 & 10 & 3 & 0.005 & 1.125 & 5.434 & 0.791 & 0.90221 & 5.23366 & 0.73251 \\
\hline 26 & 10 & 3 & 0.010 & 1.139 & 5.335 & 0.683 & 1.04444 & 5.89558 & 0.81974 \\
\hline 27 & 10 & 3 & 0.015 & 1.149 & 6.153 & 0.665 & 1.1695 & 6.49033 & 0.90697 \\
\hline
\end{tabular}


Table 5: Response table for means for Ra

\begin{tabular}{|c|c|c|c|c|c|}
\hline Level & $\mathrm{Q}$ & $\mathrm{P}$ & $\mathrm{V}_{\mathrm{w}}$ & $\mathrm{F}$ & $\mathrm{t}$ \\
\hline 1 & 0.9999 & 0.9544 & 0.9630 & 0.8005 & 0.9058 \\
\hline 2 & 0.9924 & 1.0053 & 0.9787 & 1.0297 & 1.0040 \\
\hline 3 & 0.9967 & 1.0293 & 1.0473 & 1.1588 & 1.0792 \\
\hline Delta & 0.0075 & 0.0749 & 0.0843 & 0.3583 & 0.1733 \\
\hline Rank & 5 & 4 & 3 & 1 & 2 \\
\hline
\end{tabular}

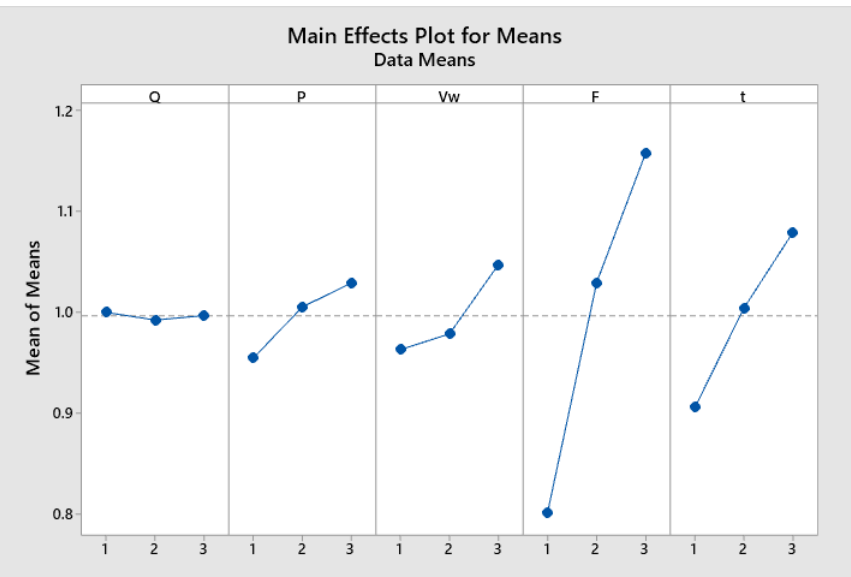

Figure 6: Main effects plot for means of $R_{a}$

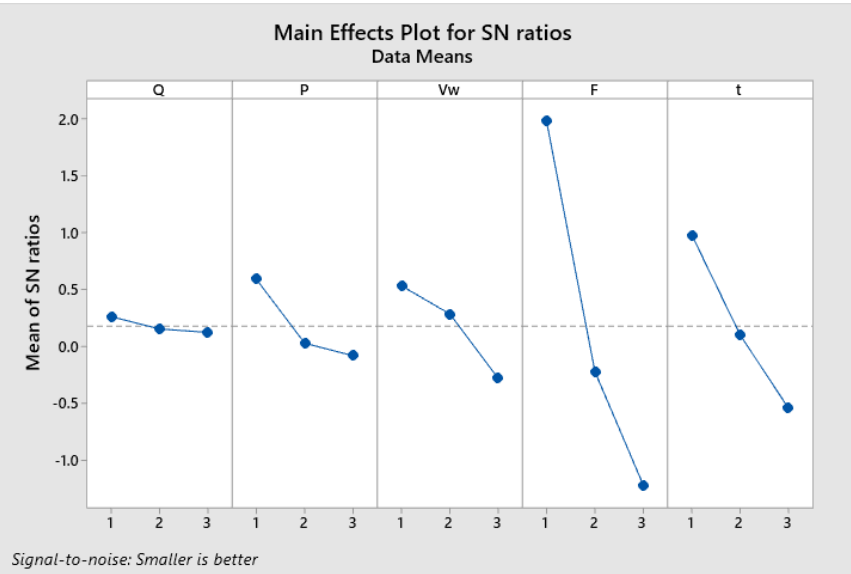

Figure 7: Main effects plot for $S N$ ratios of $R_{a}$

The data in table 4 , table 5 depict the influence of cutting and lubrication parameters on the surface roughness $R_{a}$. The cutting parameters, namely $V_{w}, F$, and $t$ affect surface roughness $R_{a}$ significantly. The influence of $F$ is the most, followed by $a_{p}$ and $V_{w}$. The lubricant parameters include $P$ and $Q$ influence on surface roughness insignificantly. When figures 6,7 present the interaction between cutting parameters with surface roughness value. The value of feed rate $f$ rising from level 1 to level 3 , the surface roughness increases quickly from $0.8 \mu \mathrm{m}$ to around $1.15 \mu \mathrm{m}$, an increase of $50 \%$. Similarly, the surface roughness rising significantly from $0.9 \mu \mathrm{m}$ to $1.1 \mu \mathrm{m}$ when the workpiece velocity $V_{w}$ increase from level 1 to level 3 . The figure for the cutting depth is fluctuating around $0.9 \mu \mathrm{m}$ to $1.0 \mu \mathrm{m}$, respectively.

The data in tables 6,7 illustrate the influence of cutting and lubrication parameters on the mean roughness depth $R_{z}$. Where, the cutting parameters influence surface roughness more significantly than the lubrication parameters. The cutting parameters include $\mathrm{Vw}$, $\mathrm{f}$, and t effect surface roughness significantly. The influence of $f$ is the most, followed by $t$ and $V_{w}$. The lubricant parameters include $P$ and $Q$ influence on surface roughness insignificantly.

\section{Influence of input factors on mean roughness depth $R_{z}$}

Table 6: Response table for signal to noise ratios for $R_{z}$

\begin{tabular}{|c|c|c|c|c|c|}
\hline Level & $\mathrm{Q}$ & $\mathrm{P}$ & $\mathrm{V}_{\mathrm{w}}$ & $\mathrm{F}$ & $\mathrm{t}$ \\
\hline 1 & -16.33 & -16.18 & -16.40 & -14.88 & -15.81 \\
\hline 2 & -16.70 & -16.66 & -16.42 & -16.73 & -16.68 \\
\hline 3 & -16.54 & -16.73 & -16.74 & -17.95 & -17.07 \\
\hline Delta & 0.37 & 0.55 & 0.33 & 3.07 & 1.27 \\
\hline Rank & 4 & 3 & 5 & 1 & 2 \\
\hline
\end{tabular}

Table 7: Response table for means for $R_{z}$

\begin{tabular}{|c|c|c|c|c|c|}
\hline Level & $\mathrm{Q}$ & $\mathrm{P}$ & $\mathrm{V}_{\mathrm{w}}$ & $\mathrm{F}$ & $\mathrm{t}$ \\
\hline 1 & 6.677 & 6.545 & 6.737 & 5.576 & 6.248 \\
\hline 2 & 6.899 & 6.872 & 6.688 & 6.884 & 6.908 \\
\hline 3 & 6.794 & 6.953 & 6.945 & 7.910 & 7.213 \\
\hline Delta & 0.222 & 0.408 & 0.257 & 2.334 & 0.966 \\
\hline Rank & 5 & 3 & 4 & 1 & 2 \\
\hline
\end{tabular}

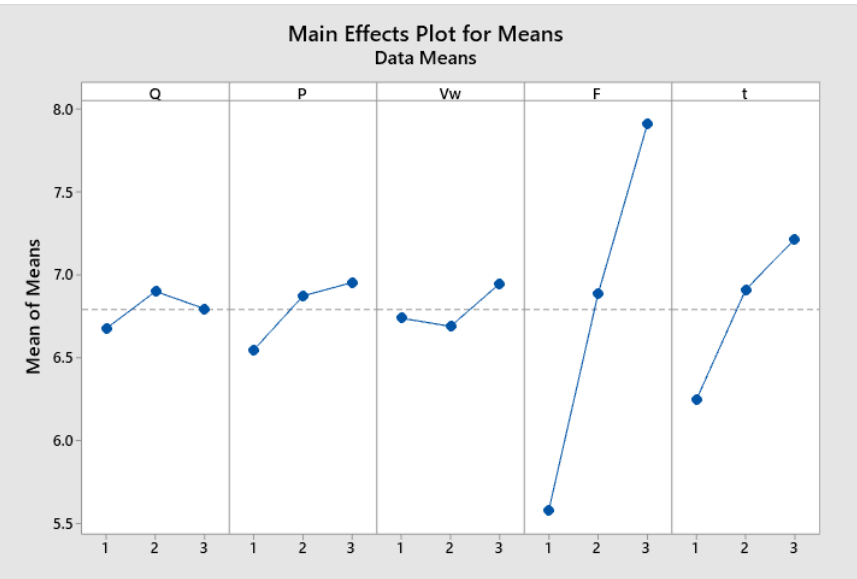

Figure 8: Main effects plot for means of $R_{z}$

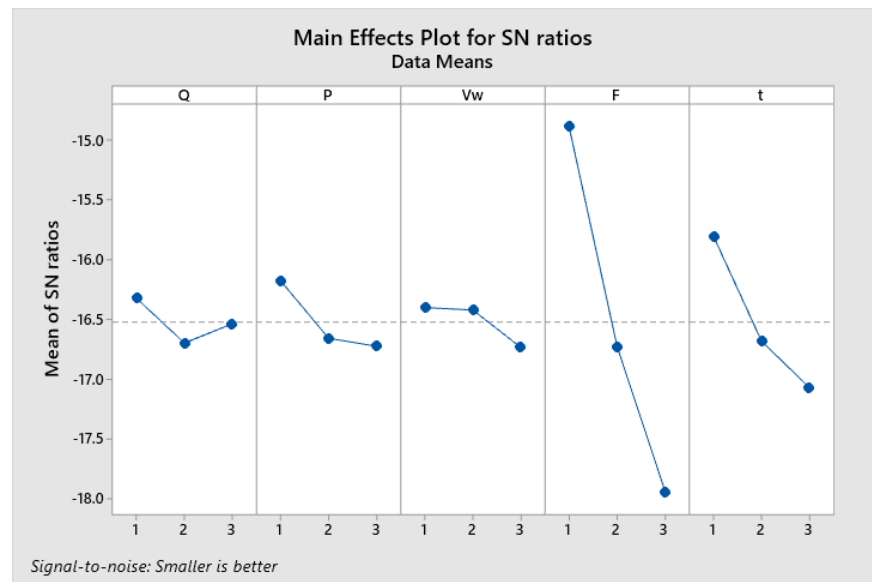

Figure 9: Main effects plot for SN Ratios of $R_{z}$ 
Besides, figures 8, 9 outline the interaction between cutting parameters with surface roughness value. The value of feed rate $f$ increase from level 1 to level 3 causes quickly increasing from $5.5 \mu \mathrm{m}$ to around $8.0 \mu \mathrm{m}$ of mean roughness depth $R_{z}$, an increase of around $40 \%$. Similarly, the surface roughness rising significantly from $6.2 \mu \mathrm{m}$ to $7.2 \mu \mathrm{m}$ when the depth of cut ap rising from level 1 to level 3. By contrast, the maximum height $R_{z}$ increases slightly from $6.9 \mu \mathrm{m}$ when $\mathrm{V}_{w}$ rising from Level 1 to level 2 , then went down significantly when the $V_{w}$ rising to the level 3 value.

\section{Influence of input factors on root mean square roughness $R_{q}$}

The data in tables 8 and 9 present the influence of cutting parameters, namely $V_{w}, f, t$, and lubrication parameters includes P, Q on the Root Mean Square Roughness (RMS Roughness) Rq. Where, the cutting parameters influence surface roughness more significantly than the lubrication parameters. By contrast, the lubricant parameters influence surface roughness insignificantly.

Figures 9 and 10 show that the values of $P, V_{w}, F$, and $t$ are proportional to RMS Roughness. That means, increasing $P, V_{w}, F$, and $t$ causes the rising value of $R S M$ Roughness. When the values of $F$ and $V w$ increase from level 1 to level 3 , the RMS roughness goes up quickly from $1.1 \mu \mathrm{m}$ to $1.5 \mu \mathrm{m}$ and $1.2 \mu \mathrm{m}$ to $1.4 \mu \mathrm{m}$, respectively. Similarly, when the depth of cut $t$ rising from level 1 to level 3 , the RMS roughness goes slightly from $1.28 \mu \mathrm{m}$ to $1.32 \mu \mathrm{m}$.

Table 8: Response table for signal to noise ratios of $R_{q}$

\begin{tabular}{|c|c|c|c|c|c|}
\hline Level & $\mathrm{Q}$ & $\mathrm{P}$ & $\mathrm{V}_{\mathrm{w}}$ & $\mathrm{F}$ & $\mathrm{t}$ \\
\hline 1 & -1.9862 & -1.4773 & -1.2879 & -0.8100 & -1.9147 \\
\hline 2 & -2.3656 & -2.4680 & -2.2251 & -2.2459 & -2.1505 \\
\hline 3 & -2.0292 & -2.4356 & -2.8679 & -3.3250 & -2.3158 \\
\hline Delta & 0.3795 & 0.9907 & 1.5800 & 2.5150 & 0.4010 \\
\hline Rank & 5 & 3 & 2 & 1 & 4 \\
\hline
\end{tabular}

Table 9: Response Table for Means of $R_{q}$

\begin{tabular}{|c|c|c|c|c|c|}
\hline Level & $\mathrm{Q}$ & $\mathrm{P}$ & $\mathrm{V}_{\mathrm{w}}$ & $\mathrm{F}$ & $\mathrm{t}$ \\
\hline 1 & 1.294 & 1.207 & 1.178 & 1.109 & 1.262 \\
\hline 2 & 1.315 & 1.329 & 1.298 & 1.296 & 1.296 \\
\hline 3 & 1.267 & 1.340 & 1.401 & 1.471 & 1.318 \\
\hline Delta & 0.048 & 0.133 & 0.223 & 0.362 & 0.056 \\
\hline Rank & 5 & 3 & 2 & 1 & 4 \\
\hline
\end{tabular}

By contrast, the influence of flow rate $Q$ is not stable. When $Q$ rising from level 1 to level 2, meaning from $50 \mathrm{ml} / \mathrm{h}$ to $100 \mathrm{ml} / \mathrm{h}$, the RMS roughness rose slightly from $1.3 \mu \mathrm{m}$ to 1.31 . However, with the continued increase of flow rate to $150 \mathrm{ml} / \mathrm{h}$ (level 3 ), the RSM roughness reduces to $1.28 \mu \mathrm{m}$.

Fig. 8, 10 and 12 also shown that each individual responses $R_{a}, R_{z}, R_{q}$ reach to optimal point at the same combination of input factors.

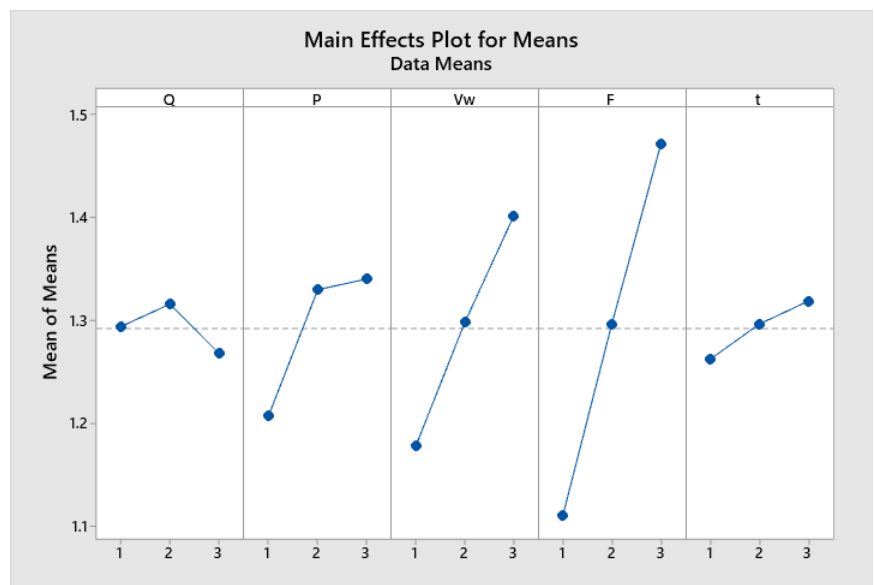

Figure 10: Main effects plot for means of $R_{q}$

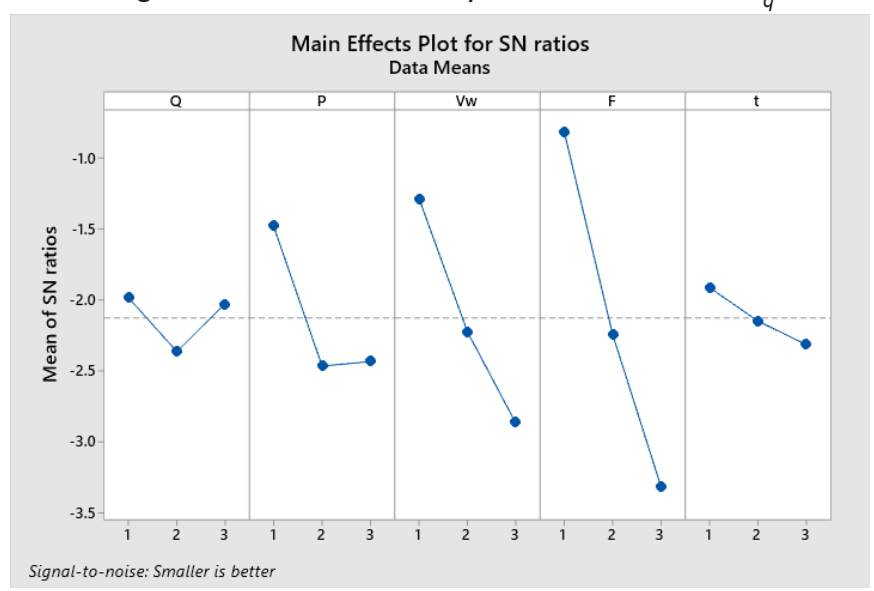

Figure 11: Main effects plot for SN Ratios of $R_{q}$

\section{Regression model}

The regression model for Surface roughness $R_{a}$, mean roughness depth $R_{z}$, Root Mean Square (RMS) Roughness $R_{q}$ were generated with the regression optimizer tool in Minitab 19, with the Box-Cox transformation selection. The regression modelsare shown as (4), (5), and (6). The regression models were applied to calculate the predicted value of $R_{a}, R_{z}, R_{q}$. The summarize of prediction and measurement of $R_{a}, R_{z}, R_{q}$ were shown in Table 3 .

The R-squared for Regression Model of $R_{a}, R_{z}, R_{q}$ are $89.08 \%, 92.42 \%$, and $95.36 \%$, respectively. That means the regression models could be applied topredict the value of surface roughness $R_{a}$, mean roughness depth $R_{z}$, and Root Mean Square Roughness $R_{q}$. The regression models were used to solve multiple optimization problems.

Regression model for surface roughness average $R_{a}$ $R_{a}=0.2190-000032 Q+0.0375 P+0.00843 V_{w}+0.0895 f+17.33 t \quad(4)$

\section{Regression model for mean roughness depth $R_{z}$}

$R_{z}^{2}=-13.83+0.0105 Q+2.270 P+0.231 V_{w}+7.846 f+1307 t$

Regression model for root mean square roughness $R_{q}$

$R_{q}^{2}=-0.345-0.0147 Q+0.1679 P+0.05625 V_{w}+0.2310 f+14.11 t \quad(6)$

Istraživanja i projektovanja za privredu ISSN 1451-4117 Journal of Applied Engineering Science Vol. 19, No. 3, 2021 
Measured vs. Predicted value of surface roughness

$\mathrm{Ra}$

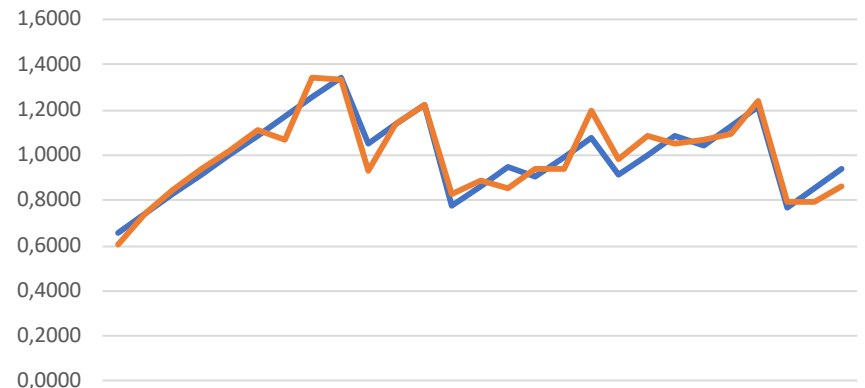

1233456789101112131415161718192021222324252627

PFITS-Ra Ra

Figure 12: Measured vs. predicted value of surface roughness $R_{\mathrm{a}}$

Measured vs. Predicted value of mean roughness depth $R_{z}$

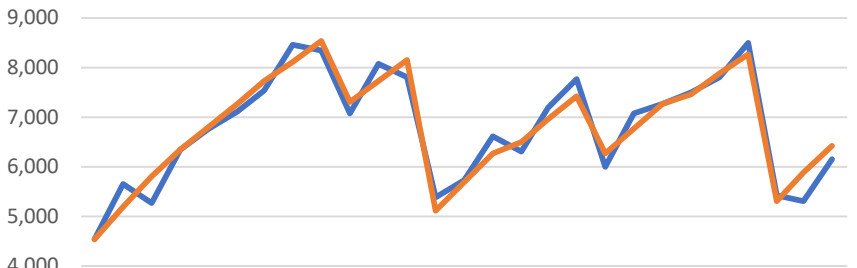

3,000

2,000

1,000

0,000
Measured vs. Predicted value of Root Mean Squaure Roughness $\mathrm{R}_{\mathrm{q}}$
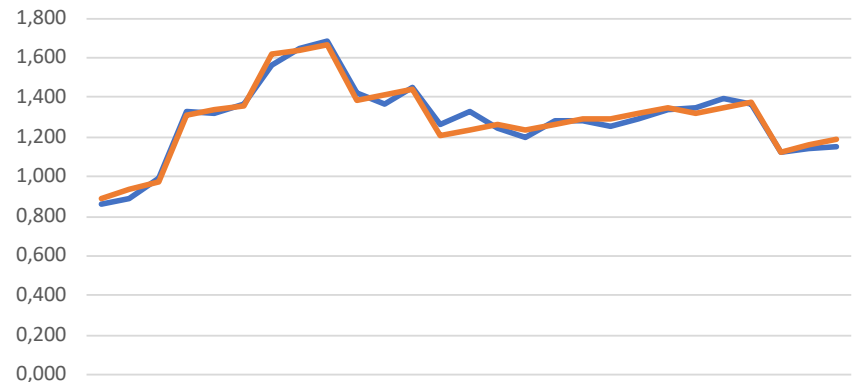

Figure 14: Measured vs. predicted value of root mean squaure roughness $R_{q}$

the minimizing of $R_{a}, R_{z}, R_{q}$ approach. The results are shown in Tables 10, 11, 12 and Figure 15.

The data from Table 10,11, 12 and Figure 15 shown that optimum cutting parameters as: workpiece velocity $V_{w}$, feed rate $\mathrm{f}$, depth of cut ap are $5 \mathrm{~m} / \mathrm{min}, 3 \mathrm{~mm} /$ stroke, $0.005 \mathrm{~mm}$, respectively, corresponding to the optimum lu-

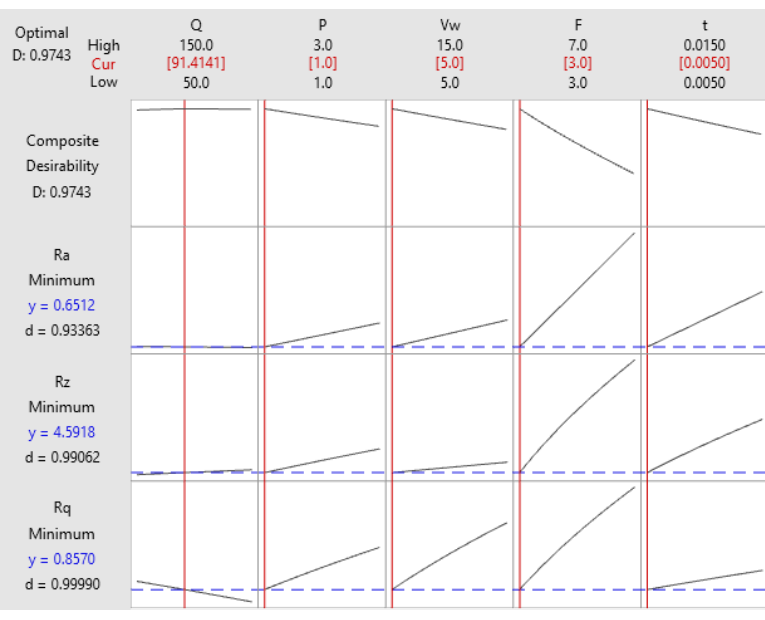

Figure 15: Multiple optimization of $R_{a}, R_{z}, R_{q}$ used to solve the multiple optimization problems, with

Table 10: Parameters of multiple optimization problems

\begin{tabular}{|c|c|c|c|c|c|c|}
\hline Response & Goal & Lower & Target & Upper & Weight & Importance \\
\hline $\mathrm{R}_{\mathrm{a}}$ & Minimum & & 0.60200 & 1.34267 & 1 & 1 \\
\hline $\mathrm{R}_{\mathrm{z}}$ & Minimum & & 4.55467 & 8.51200 & 1 & 1 \\
\hline $\mathrm{R}_{\mathrm{q}}$ & Minimum & & 0.85690 & 1.68420 & 1 & 1 \\
\hline
\end{tabular}

Table 11: The solution of multiple optimization problems

\begin{tabular}{|c|c|c|c|c|c|c|c|c|c|}
\hline Solution & $\mathrm{Q}$ & $\mathrm{P}$ & $\mathrm{V}_{\mathrm{w}}$ & $\mathrm{F}$ & $\mathrm{a}_{\mathrm{p}}$ & $\mathrm{R}_{\mathrm{a}} \mathrm{Fit}$ & $\mathrm{R}_{\mathrm{z}} \mathrm{Fit}$ & $\mathrm{R}_{\mathrm{q}} \mathrm{Fit}$ & Composite Desirability \\
\hline 1 & 91.4141 & 1 & 5 & 3 & 0.005 & 0.651159 & 4.59178 & 0.856980 & 0.974272 \\
\hline
\end{tabular}

Table 12: The multiple response prediction of multiple optimization

\begin{tabular}{|c|c|c|c|c|c|c|}
\hline Variable & Setting & Response & Fit & SE Fit & $95 \% \mathrm{Cl}$ & $95 \% \mathrm{PI}$ \\
\hline $\mathrm{Q}$ & 91.4141 & $\mathrm{R}_{\mathrm{a}}$ & 0.6512 & 0.0342 & $(0.5799,0.7224)$ & $(0.4946,0.8077)$ \\
\hline $\mathrm{P}$ & 1 & $\mathrm{R}_{\mathrm{z}}$ & 4.592 & $*$ & $(4.092,5.042)$ & $(3.399,5.533)$ \\
\hline $\mathrm{V}_{\mathrm{w}}$ & 5 & $\mathrm{R}_{\mathrm{q}}$ & 0.8570 & $*$ & $(0.7891,0.9199)$ & $(0.6991,0.9900)$ \\
\hline $\mathrm{f}$ & 3 & & & & & \\
\hline $\mathrm{a}_{\mathrm{p}}$ & 0.005 & & & & & \\
\hline
\end{tabular}


brication parameters as oil flow rate of $91.94 \mathrm{ml} / \mathrm{h}$ and air pressure of $1 \mathrm{MPa}$. Corresponding to the surface roughness $R_{a}$, root mean square roughness $R_{q}$, and mean roughness depth $R_{z}$ of $0.6512 \mu \mathrm{m}$.

\section{CONCLUSION}

In summary, this paper argued that:

- The feed rate $f$ effect the most on the whole surface roughness $R_{a}$, Root Mean Square Roughness $R_{q}$, and Mean Roughness Depth $R_{z}$, followed by workpiece velocity $V_{w}$. The depth of cut ap effect on the roughness values insignificant.

- The lubricant variants had an insignificant influence on $\mathrm{R}_{\mathrm{a}}, \mathrm{R}_{\mathrm{z}}, \mathrm{R}_{\mathrm{q}}$

- In this experimental study, grinding of hardened S50C carbon steel was the first performed with assisted Vietnamese peanut oil as minimum quantity lubricant.

- The present findings confirm vegetable oil's ability based as the lubricant in the cutting process, including grinding. The combining grinding and lubricant parameters as following: The workpiece velocity $\mathrm{Vw}$ of $5 \mathrm{~m} / \mathrm{min}$, feed rate $\mathrm{f}$ of $3 \mathrm{~mm} / \mathrm{stroke}$, depth of cut of $0.005 \mathrm{~mm}$ and oil flow rate, air pressure of 91.94 $\mathrm{ml} / \mathrm{h}, 1 \mathrm{MPa}$, respectively. Corresponding to the surface roughness $R_{a}$, Root Mean Square Roughness $R_{q}$, and Mean Roughness Depth $R_{z}$ of $0.6512 \mu m$, $4.592 \mu \mathrm{m}, 0.8570 \mu \mathrm{m}$.

- Computing software Minitab could be applied to generate the regression models and solve the multiple objective optimization problems.

- The effects of the combinations of input variables on $\mathrm{Ra}, \mathrm{Rz}, \mathrm{Rq}$ are quite similar. Hence, It's sufficient to research only one of response $R_{a}, R_{z}$ or $R_{q}$.

\section{ACKNOWLEDGMENT}

The authors highly appreciate the support from Hanoi University of Industry (HaUl-https://haui.edu.vn) for this present research.

\section{REFERENCES}

1. A. Anand, K. Vohra, M. I. UI Haq, A. Raina, and M. Wani (2016), "Tribology in Industry Tribological Considerations of Cutting Fluids in Machining Environment: A Review Corresponding author,"Tribol. Ind., vol. 463, pp. 463-474,

2. H. Dung, N.-T. Nguyen, and D. Trung (2020), "Calculation of Residual Stress on the Surface Layer of Workpiece When Surface Grinding the Aisi 1018 Steel," vol. 15, pp. 2229-2233, doi: 10.36478/jeasci.2020.2229.2233.
3. H. Hegab, B. Darras, and H. A. Kishawy (2018), "Sustainability Assessment of Machining with $\mathrm{Na}$ no-Cutting Fluids,"Procedia Manuf., vol. 26, pp. 245-254, doi: 10.1016/j.promfg.2018.07.033.

4. M. J. Hadad, T. Tawakoli, M. H. Sadeghi, and B. Sadeghi (2012), "Temperature and energy partition in minimum quantity lubrication-MQL grinding process,"Int. J. Mach. Tools Manuf., vol. 54-55, pp. 10-17, doi: https://doi.org/10.1016/j.ijmachtools.2011.11.010.

5. A. S. Awale, M. Vashista, and M. Z. Khan Yusufzai (2020), "Multi-objective optimization of MQL mist parameters for eco-friendly grinding,"J. Manuf. Process., vol. 56, pp. 75-86, doi: https://doi. org/10.1016/j.jmapro.2020.04.069.

6. L. Hung-Chang and C. Yan-Kwang (2002), "Optimizing multi-response problem in the Taguchi method by DEA based ranking method,"Int. J. Qual. Reliab. Manag., vol. 19, no. 7, pp. 825-837, doi: 10.1108/02656710210434766.

7. M. Mia et al. (2018), "Taguchi S/N based optimization of machining parameters for surface roughness, tool wear and material removal rate in hard turning under MQL cutting condition,"Meas. J. Int. Meas. Confed., vol. 122, pp. 380-391, doi: 10.1016/j.measurement.2018.02.016.

8. K. M. Senthilkumar, R. Thirumalai, T. A. Selvam, A. Natarajan, and T. Ganesan (2020), "Multi objective optimization in machining of Inconel 718 using taguchi method,"Mater. Today Proc., doi: https://doi. org/10.1016/j.matpr.2020.09.333.

9. C. M., (2013), "A coupling method of response surfaces (CRSM) for cutting parameters optimization in machining titanium alloy under minimum quantity lubrication (MQL) condition,"Int. J. Precis. Eng. Manuf., vol. 14, p. 693.

10. X.-C. Cao, B.-Q. Chen, B. Yao, and W.-P. He (2018), "Combining translation-invariant wavelet frames and convolutional neural network for intelligent tool wear state identification,"Comput. Ind., vol. 106, pp. 71-84, doi: https://doi.org/10.1016/j.compind.2018.12.018. 
11. C. Cooper et al. (2020), "Convolutional neural network-based tool condition monitoring in vertical milling operations using acoustic signals,"Procedia Manuf., vol. 49, pp. 105-111, doi: https://doi. org/10.1016/j.promfg.2020.07.004.

12. W. Yu et al. (2019), "Predictive control of CO2 emissions from a grate boiler based on fuel nature structures using intelligent neural network and Box-Behnken design,"Energy Procedia, vol. 158, pp. 364-369, doi: https://doi.org/10.1016/j.egypro.2019.01.116.
13. N. Ghosh et al. (2007), "Estimation of tool wear during CNC milling using neural network-based sensor fusion,"Mech. Syst. Signal Process., vol. 21, no. 1, pp. 466-479, doi: https://doi.org/10.1016/j.ymssp.2005.10.010.

14. OLYMPUS CORPORATION, Profile Method (Linear Roughness) Parameters, from https://www.olympus-ims.com/en/metrology/surface-roughness-measurement-portal/parameters/. 